\title{
NASAL CARRIAGE OF STAPHYLOCOCCUS AUREUS IN NURSES \\ BY
}

\author{
J. G. P. HUTCHISON, C. A. GREEN, AND T. A. GRIMSON \\ From the Department of Bacteriology, Royal Victoria Infirmary, Newcastle upon Tyne
}

(RECEIVED FOR PUBLICATION JANUARY 16, 1956)

A persistent nasal carrier of Staphylococcus aureus tends to harbour the same phage type of organism for many months (Williams, 1946: Rountree and Barbour, 1951: Gould and McKillop, 1954). At the same time it has been shown that nurses in hospital possess a high carriage rate for penicillin-resistant Staph. aureus (Barber, Hayhoe, and Whitehead, 1949 ; Rountree and Thomson, 1952 ; Barber, Wilson, Rippon, and Williams, 1953), a condition not obtaining in the population at large. Furthermore, a high carriage rate for an epidemic or hospital strain has been observed in the noses of the nursing staff (Allison and Hobbs, 1947 ; Forbes, 1949 ; Barber et al., 1949). The question arises as to how the persistence of a single type in an individual is influenced by hospital conditions. An answer to this query was sought by observing nurses during their training period and subsequent employment on ward duties. A similar investigation was made by Rountree and Barbour (1951), and the present account provides further detail of the changes which take place under these circumstances.

\section{Material Studied}

From four groups of trainee nurses (about 30 per group) nasal swabs were taken at weekly intervals for periods varying from six to 23 weeks. Some of the nurses had already worked in hospital, but just over half were newcomers to a hospital environment. All the nurses lived together during the first 10 weeks of the study in a hostel, separated from the main hospital, each bedroom having two occupants. For the first seven weeks of the period, apart from two or three organized visits en masse to various hospital departments, no contact with the hospital was made officially, save indirectly through the sister tutors and the communal use of the hospital laundry. From the eighth to tenth weeks each nurse spent two hours a day in the hospital wards, bed making, etc. After completing the training course in the tenth week, nurses were engaged full time on ward duty and lived in a home attached to the main hospital. $N$ Thus four groups of nurses underwent training for $ᄋ$ the 10-week period during the course of one year.

The first of the groups was reviewed a year after their initial training period when, for three weeks, they returned to a hostel, apart from the main hospital, for a revision course. During this time nasal swabs were taken twice a week. In the latter part of the study, when it was possible to swab pro- Vy gressively fewer girls (owing to holidays, night duty, etc.), the same few attended regularly to the end.

\section{Methods}

Broth-soaked swabs were used throughout. these being plated directly on to the horse-blood agar. All coagulase-positive staphylococci (Cadness-Graves. 3 Williams, Harper, and Miles, 1943, or Fisk, 1940) were $\bar{\supset}$ subjected to typing by bacteriophage (Williams and Rippon, 1952) and to antibiotic sensitivity tests (Hutchison, 1954). Strains were regarded as sensitive $\frac{8}{0}$ if inhibited by penicillin ( 1 unit per $\mathrm{ml}$. or less), 웅 streptomycin $(10 ": \mathrm{g}$. per ml.), chloromycetin $(20 \mu \mathrm{g} .3$. per $\mathrm{ml}$.), and terramycin $(4 \mu \mathrm{g}$. per $\mathrm{ml}$.). the antibiotics 8 being incorporated in blood agar.

\section{Results}

The results from the four groups of girls have been added together on the basis of time in weeks $N$ from the beginning of their training course, and 5 Tables I and II summarize the findings from a $N$ total of 117 girls. After the sixth week specimens $\underset{\omega}{N}$ from one group of 28 were discontinued, and after 0 the 17 th week in the three remaining groups the 0 numbers available dropped so that the percentages towards the end of the study (18th and 23rd week) $\stackrel{\odot}{?}$ have less significance.

Carriage Rate for Staph. aureus.-Table $I \stackrel{0}{\stackrel{D}{D}}$

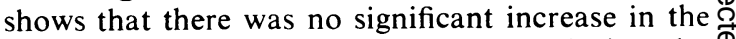
nasal carriage rate for Staph. aureus during the $\mathbb{\complement}$ study. The original four groups of girls were found to have carriage rates varying from 37.58 
$\pm 9.1 \%$ to $60.6 \pm 9.5 \%$ in the first week of the study. Each group was composed roughly of equal numbers with and without previous hospital contact, whose carriage rates were $56.9 \%$ and $40.4 \%$ respectively, the difference being insignificant, and falling within the observed rates quoted above for each original group.

Antibiotic Resistance of Strains.-The carriage rate for penicillin-resistant strains in the first week of the study was higher than the figure of $6 \%$ recorded for the general population of this same area (Hutchison and Bowman, unpublished data). Separation of the girls into the categories with and without previous hospital contact showed that in the former the penicillin-resistant carrier rate was $15 \%$, whereas in the latter it was $4 \%$, suggesting some residual carriage of resistant strains in the former group.

Table I indicates that from weeks 1 to 10 no change beyond the expected variation was found in the penicillin-resistant carrier rate. However, the presence of two chloromycetin-resistant strains (fifth and tenth weeks) and the acquisition of some streptomycin-resistant strains (weeks 2 to 10), both of which were rare in the general population, suggested that in fact resistant "hospital " strains were already colonizing the nares. The only streptomycin-resistant strain isolated in the first week came from a girl who had had two years in hospital wards, but in the second week a girl with no previous hospital contact was carrying a streptomycin-resistant strain.

After the tenth week, when full-time ward duties began, the rise in the penicillin-resistant carrier rate became marked, reaching a statistically significant level in the 12 th week $(27 \%)$ and rising to a mean value of $44 \%$ in weeks 21 to 23 . The results for streptomycin and chloromycetin followed a similar course, though the incidence of resistant strains was considerably less than that for penicillin. Terramycin-resistant strains were found on only four occasions in a single individual, due, no doubt, to the limited use of this drug in the hospital.

Phage Type of Strains.-In the first week, Group I strains accounted for $31.6 \%$ of those isolated, Group II for $14.0 \%$, Group III for $15.8 \%$ and strains not typable with phage filtrates at

TABLE I

NASAL CA RRIAGE RATE FOR STAPH. AUREUS AND ANTIBIOTIC RESISTANCE RATE OF STRAINS ISOLATED FROM NURSES DURING SUCCESSIVE PHASES OF OBSERVATION PERIOD

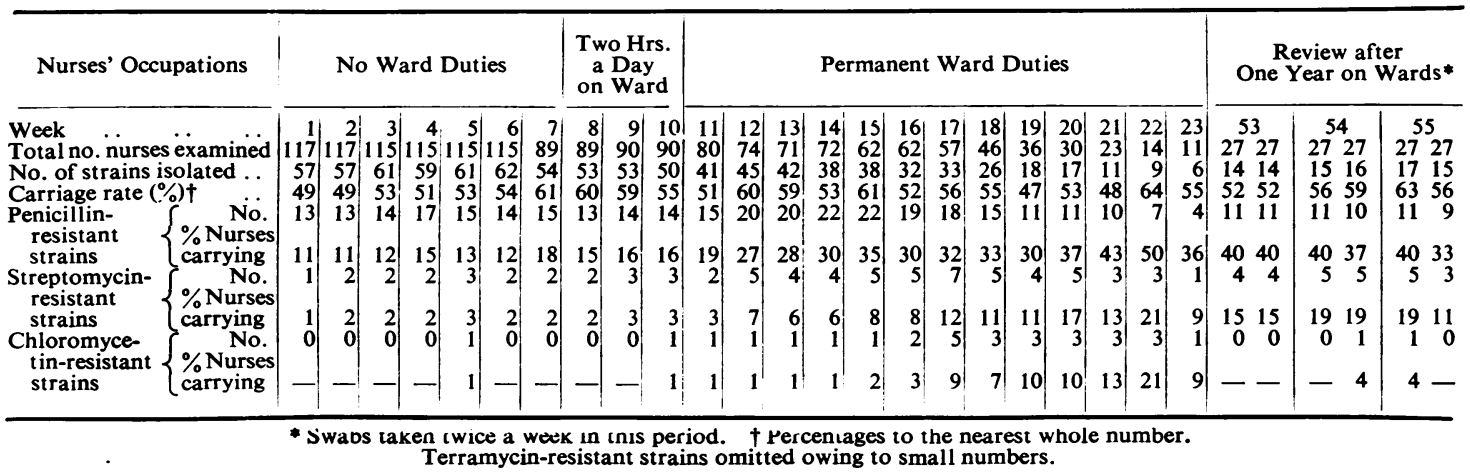

TABLE II

INCIDENCE OF PHAGE GROUP I (52), GROUP II (3A), GROUP III (6 47) AND OF STAPHYLOCOCCAL STRAINS UNTY PABLE AT ROUTINE TEST DILUTION

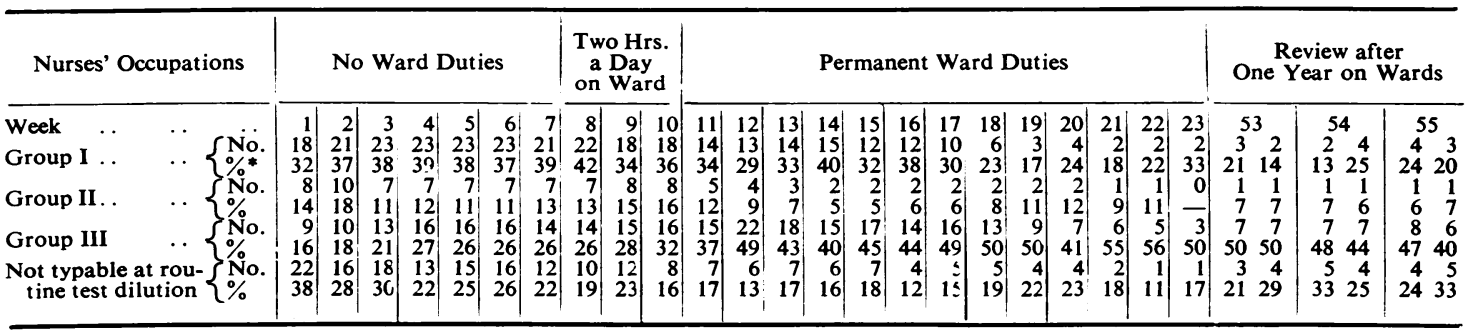

* Percentages to the nearest whole number. 
routine test dilution (Williams and Rippon, 1952) for $38.6 \%$ (Table II). With the exception of Group I strains, the figures were in close agreement with those of Williams, Rippon, and Dowsett (1953) for nasal specimens from normal persons: Group I, $21.8 \%$, Group II, $13.1 \%$, Group III, $17.5 \%$, and not typable at routine test dilution $42 \%$.

As the study progressed the incidence of Group III strains rose until they became predominant in the 11th week when nurses were on full-time ward employment. This upward trend was suggested by the data available from the first week onward and confirmed to some extent by a similar increase in the incidence of antibiotic-resistant strains. Coincidentally, Group II and untypable strains became progressively less common, while Group I strains remained fairly steady. It was clear that the nurses had acquired polyantibiotic-resistant Group III strains of Staph. aureus which were known to be prevalent in the hospital at that time, but which were rare in the general population. Conversely they were losing the Group II and untypable strains. In the case of Group I strains, however, reference to the "carriage history" of each individual showed that loss and gain of these strains was a frequent occurrence in those who might be termed "temporary carriers," but that Group I strains gained after the tenth week were usually penicillin-resistant. It was therefore presumed that penicillin-resistant Group I strains were prevalent in the hospital, along with the Group III strains already mentioned. At the same time the occurrence of penicillin-resistant Group I strains in the general population and their failure to develop resistance to antibiotics other than penicillin rendered these more difficult to incriminate as hospital organisms. This interpretation may correlate the relatively static Group I percentages observed with an increasing number of penicillin-resistant strains.

An attempt was made to determine whether under hostel or dormitory conditions crosscolonization occurred within each trainee group, but no evidence to this effect was obtained.

Persistence of Carriage of Staph. aureus : Positive.-Twenty-five $(28 \%)$ of 91 girls persistently carried a single phage type for the first 10 weeks and $19(21 \%)$ for 17 weeks or more. Of 27 girls in the reviewed group, two carried the same phage type for nine months and two for over a year. None of those persistently positive for the first 10 weeks became negative during their follow-up on the wards, but three originally persistent carriers were found negative after a year on review. Eight girls who were persistent carriers of a single type for nine or more weeks changed types and became $\stackrel{\overrightarrow{\bar{S}}}{\vec{P}}$ persistent carriers of another type.

Persistence of Carriage of Staph. aureus : Negative.-Twenty-three $(25 \%)$ of 91 girls were per-

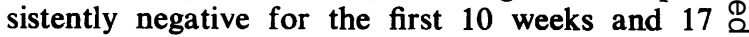
$(19 \%)$ for 17 weeks or more. Six of $27(22 \%)$ were still negative after over a year at review. $\vec{\circ}$ Five who had proved negative for the first 10 . weeks subsequently became persistent carriers.

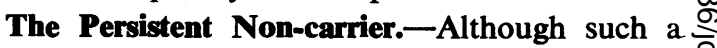
state has been inferred from time to time by those ? who have made repeated examinations on the $\vec{\circ}$ same individuals (Miles, Williams, and ClaytonCooper, 1944 ; Packalen and Bergqvist, 1947 ; i Rountree and Barbour, 1951), others have not $ᄋ$ remarked or have not encountered the persistently negative person (Williams, 1946; Gould and T McKillop, 1954). In this series, even under ward conditions, about $20 \%$ of girls appeared abnormally resistant to nasal colonization of Staph. aureus. Similar observations have also been made in the staff of a maternity hospital (Hutchison and Bowman, unpublished data). This state of affairs is perhaps more interesting than persistent carriage.

If there is an immunity to the nasal carriage of Staph. aureus, upon what does it depend ? Moss, Squire, and Topley (1948) unsuccessfully attempted to correlate nasal deformities with the predisposition to staphylococcal carriage, and therefore the absence of such deformities is unlikely to produce a non-carrier. Immunity to carriage has apparently nothing to do with the humoral immunity of the individual, for Packalen and Bergqvist (1947) showed that it was the noncarrier, not the persistent carrier, who possessed the lowest antitoxin level. It may be that some people have an abnormally high lysozyme or "inhibine" (Dold and Weigmann, 1934 ; Ignatius, 1936) content in the nasal mucus which suffices to determine the persistent non-carrier state under the most adverse circumstances.

\section{Discussion}

The finding that about $20 \%$ of girls were persistent carriers and that a roughly equal percentage were abnormally resistant to carriage leaves the remaining $60 \%$ in the "temporary-carrier" class (persons liable to acquire and lose strains frequently). Whereas the former two groups were relatively stable in carriage pattern the latter was by definition unstable and liable to undergo change with a change of environment.

The answer to the apparent discrepancy between permanence of staphylococcal carriage in some 
individuals and the rapid increase in some communities of antibiotic-resistant strains, with or without a significant increase in overall carriage rate, is to be found in the realm of the temporary carrier. If, of 100 persons, 20 are persistent carriers, 20 persistent non-carriers, and, of the remaining 60 temporary carriers, 25 are positive and 35 negative at any instant, the single swab carrier rate will be $45 \%$ (a usual figure). Should this same group of persons be transferred to the hospital environment then an increase in the number of carriers amongst those of the "temporary" class from 25 to 40 could take place before a statistically signficant increase in the overall carriage rate $(60 \%)$ was observed. The initial carriers of this class need not necessarily still be carriers, so that a number, say 35 of the 40 fresh strains acquired in hospital, would tend to be penicillinresistant. A penicillin-resistant carrier rate of $35 \%$ could thus be achieved without imposing any change in persistent carriers or non-carriers. In fact some permanent carriers of this series became carriers of resistant strains, and categories mentioned cannot be considered as absolute but more in the nature of a gradation from one end of the scale to the other. The findings of Rountree and Barbour (1951) appear consistent with this view.

The corollary is that those who are more liable to acquire hospital strains, the temporary carriers, are also more prone to relinquish them when environmental conditions return to normal.

It is suggested that superinfection of a nurse's nose occurs frequently during bed making and other duties when masks would not normally be worn. It may be that efficient masking is not merely a protection to the patient but also to his attendants.

\section{Summary}

Four groups of trainee nurses were followed at weekly intervals during preliminary training and subsequent ward duties to determine the effect of change of environment on the nasal carriage of Staph. aureus.

An increase in incidence of penicillin-resistant strains was found together with a less marked increase in the number of strains resistant to other antibiotics beginning within the first week of ward duties.

Twenty per cent. of girls were persistent carriers and an equal proportion were abnormally resistant to carriage ; the remaining $60 \%$ of temporary carriers appeared more susceptible to a change of environment.

There was no significant increase in the nasal carriage rate nor could transference of strains from nurse to nurse be demonstrated during the training period.

We acknowledge with gratitude the patience and forbearance of the nurses who volunteered for this study, the assistance of the technical staff of the Department, and the co-operation of the Matron, Miss J. Hutton, and Sistor Tutor, Miss M. F. Dixon. Thanks are also due to Dr. R. E. O. Williams and Miss Joan Rippon, of the Staphylococcal Reference Laboratory, Colindale, for teaching one of us the technique of phage typing.

\section{REFERENCES}

Allison, V. D., and Hobbs, B. (1947). Brit. med. J., 2, 1.

Barber, M., Hayhoe, F. G. J., and Whitehead, J. E. M. (1949). Lancet, 2, 1120.

Wilson, B. D. R., Rippon, J. E., and Williams, R. E. O. (1953). J. Obstet. Gynaec. Brit. Emp., 60, 476.

Cadness-Graves, B., Williams, R., Harper, G. J., and Miles, A. A. (1943). Lancet, 1, 736.

Dold, H., and Weigmann, F. (1934). Z. Hyg. InfektKr., 116, 158.

Fisk, A. (1940). Brit. J. exp. Path., $21,311$.

Forbes, G. B. (1949). Brit. med. J., 2, 569.

Gould, J. C., and McKillop, E. (1954). J. Hyg. (Lond.), 52, 304.

Hutchison, J. G. P. (1954). Journal of Clinical Pathology, 7, 350.

Ignatius, A. (1936). Z. Hyg. InfektKr., 118, 445.

Miles, A. A., Williams, R. E. O., and Clayton-Cooper, B. (1944). J. Path. Bact., 56, 513.

Moss, B., Squire, J. R., and Topley, E. (1948). Lancet, 1, 320.

Packalen, T., and Bergqvist, S. (1947). A cta med. scar.d., 127, 291.

Rountree, P. M., and Barbour, R.G. H. (1951). J. Path. Bact., 63, 313. and Thomson, E. F. (1952). Lancet, 2, 262.

Williams, R. E. O. (1946). J. Path. Bact., 58, 259. and Rippon, J. E. (1952). J. Hyg. (Lond.), 50, 320.

- and Dowsett, L. M. (1953). Lancet, 1, 510. 